\title{
Analisis Cluster Longitudinal pada Pembangunan Manusia di Sulawesi Selatan Berbasis Gender
}

\author{
Khalilah Nurfadilah \\ Universitas Islam Negeri Alauddin Makassar, khalilahnurfadilah1202@gmail.com
}

\begin{abstract}
ABSTRAK Disparitas capaian IPG dan IDG masih relatif tinggi antar kabupaten/kota di Sulawesi Selatan. Masalah lain yang muncul pada pembangunan manusia di Sulawesi Selatan adalah capaian IPG yang tinggi namun tingkat IPM rendah dan sebaliknya capaian IPM yang tinggi namun IPG rendah. Perlu formulasi khusus untuk menetapkan pendekatan pembangunan yang berorientasi pada kesetaraan dan keadilan gender. Salah satu solusinya adalah dengan mengklasifikasikan kabupaten/kota berdasarkan capaian IPM, IPG, dan IDG sehingga intervensi pemerintah tepat sasaran. Klasifikasi dilakukan dengan metode analisis Cluster Longitudinal dengan metode K-Means jarak Manhattan. Ruang lingkup penelitian terdiri dari 24 kabupaten/Kota di Sulawesi Selatan pada periode waktu 2010-2020. Hasil dari Calinski \& Harabasz Criterion menunjukkan cluster optimum sebanyak 6 cluster. Pembahasan hasil menunjukkan bahwa daerah perkotaan di Sulawesi Selatan relatif lebih sukses dalam pembangunan manusia berbasis gender, dapat dibuktikan dengan cluster $\mathrm{E}$ yang beranggotakan kota Makassar, Parepare, dan Palopo dengan kategori IPM perempuan, IPG, dan IDG yang relatif tinggi dibandingkan cluster lain. Sedangkan kabupaten pada cluster C, walaupun IDG-nya relatif tinggi namun capaian IPM perempuan dan IPG relatif rendah.
\end{abstract}

Kata Kunci: Cluster Longitudinal, IPG, IDG, jarak Manhattan, K-Means

\section{PENDAHULUAN}

Menurut data Badan Pusat Statistik (BPS), sejak tahun 2017 capaian Indeks Pembangunan Manusia (IPM) di Sulawesi Selatan telah masuk kategori tinggi yang menunjukkan keseriusan pemerintah terhadap pembangunan yang tidak hanya dititikberatkan terhadap infrastrutur saja, tetapi juga manusianya. Namun, keberhasilan pembangunan manusia ini belum sepenuhnya berhasil, jika dipilah berdasarkan jenis kelamin, capaian IPM masih menunjukkan kesenjangan pada perempuan.

Menurut data BPS pada tahun 2020, capaian IPM laki-laki di Sulawesi Selatan telah masuk kategori tinggi yaitu 75,90 sedangkan capaian IPM perempuan Sulawesi Selatan yaitu 70,48 masuk juga kategori tinggi, namun selisihnya masih relatif tinggi. Padahal, dalam
Rencana Pembangunan Jangka Menengah Nasional (RPJMN) 2020-2024 telah mengarusutamakan Sustainable Development Goals (SDGs) dimana kesetaraan gender menjadi salah satu tujuan utama yang harus diwujudkan pada tahun 2030[1].

Alat ukur yang digunakan untuk mengevaluasi hasil pembangunan yang berperspektif gender antara lain adalah Indeks Pemberdayaan Gender (IDG) dan Indeks Pembangunan Gender (IPG). Menilik dari alat ukur tersebut, capaian IPG dan IDG Sulawesi Selatan pada tahun 2020 relatif tinggi, yaitu masing-masing sebesar 92,86 dan 76,32 yang melebihi capaian IPG dan IDG nasional[2]. Namun capaian ini belum menyeluruh sampai ke level kabupaten/kota. Dari 24 kabupaten/kota di Sulawesi Selatan, baru 11 kabupaten/kota yang IPG diatas capaian provinsi, bahkan hanya 4 kabupaten/kota yang capaian IDG diatas provinsi.

Disparitas capaian IPG dan IDG masih relatif tinggi antar kabupaten/kota di Sulawesi Selatan. Masalah lain yang muncul pada pembangunan manusia di Sulawesi Selatan adalah capaian IPG yang tinggi namun tingkat IPM rendah dan sebaliknya capaian IPM yang tinggi namun IPG rendah[3].

Pemangku kebijakan perlu formulasi khusus untuk menetapkan pendekatan pembangunan yang berorientasi pada kesetaraan dan keadilan gender. Salah satu solusinya adalah dengan mengklasifikasikan kabupaten/kota berdasarkan capaian IPM, IPG, dan IDG sehingga intervensi pemerintah tepat sasaran. Klasifikasi dilakukan dengan metode analisis Cluster Longitudinal yang lebih kompleks dan terukur dibanding analisis cluster data cross section[4].

Analisis cluster longitudinal terdiri dari berbagai macam metode, salah satunya metode K-Means dengan jarak Manhattan yang lebih optimim dibandingkan jarak Ecludean, 
Maximum, Frechet dan Dynamic Time Warping[5].

\section{TINJAUANPUSTAKA}

\section{Indeks Pembangunan Gender}

Indeks pembangunan gender adalah perbandingan antara IPM laki-laki dan IPM perempuan ditinjau dari aspek kualitas dimensi pendidikan, kesehatan, dan ekonomi. Dimensi pendidikan menggunakan harapan lama sekolah dan rata-rata lama sekolah, dimensi kesehatan menggunakan angka harapan hidup, dan dimensi ekonomi menggunakan pengeluaran perkapita. Angka IPG yang menghampiri 100 menunjukkan bahwa pencapaian pembangunan perempuan hamper sama dengan laki-laki. Secara persamaan, IPG dapat dirumuskan sebagai berikut[6] :

$$
I P G=\frac{I P M_{\text {laki-laki }}}{I P M_{\text {perempuan }}}
$$

\section{Indeks Pemberdayaan Gender}

Indeks pemberdayaan perempuan digunakan untuk mengukur partisipasi aktif perempuan di bidang ekonomi, politik, dan manajerial. Tiga indikator yang digunakan yaitu distribusi pendapatan perempuan terhadap pendapatan kerja, keterwakilan perempuan di parlemen, dan keterlibatan perempuan dalam pengambilan keputusan melalui indikator perempuan sebagai tenaga manajerial, professional, administrasi, dan teknisi[7].

\section{Analisis Cluster}

Analisis cluster bertujuan untuk menggabungkan beberapa objek kedalam kelompok-kelompok berdasarkan sifat kemiripan atau sifat ketidakmiripan antar objek[8]. Ada dua metode dalam analisis cluster, yaitu :

1. Metode berhierarki : dimulai dengan mengelompokkan dua atau lebih objek yang mempunyai kesamaan paling dekat. Kemudian dilanjutkan ke objek lain yang mempunya kedekatan kedua, demikian seterusnya sehingga klaster terbentuk semacam pohon berhierarki antara objek.
Untuk memperjelas proses hierarki digunakan dendogram.

2. Metode tak berhierarki : apabila banyaknya kelompok yang akan dibentuk sudah diketahui. Metode $K$-means merupakan salah satu contohnya. Pada metode $K$-means, besaran $k$ ditentukan terlebih dahulu.

\section{K-Means}

Metode $K$-means berupaya mempartisi data yang ada kedalam bentuk satu atau lebih klaster, sehingga data dengan karakteristik yang sama diklaster dalam satu kelompok yang sama. Berikut adalah algoritma dari $K$-means :

1. Penentuan jumlah kelompok dan alokasikan data kedalam kelompok secara acak.

2. Tentukan centroid setiap kelompok dengan mengambil rata-rata semua nilai dari setiap fiturnya. Persemaaan centroid fitur ke- $i$ sebagai berikut :

$$
C^{1}=\frac{1}{M} \sum_{j=1}^{M} X_{j}
$$

Dimana $M$ adalah jumlah data dalam kelompok, $i$ adalah fitur ke- $i$, dan $\mathrm{p}$ adalah dimensi data. Persamaan diatas dilakukan sebanyak $p$ dimensi $i=1$ sampai dengan $i=p$.

3. Masing-masing data dialokasikan ke centroid terdekat. Salah satu metode pengukuran yang digunakan adalah jarak Euclidean dengan persamaan berikut :

$$
d=\sqrt{\left(x_{1}-x_{2}\right)^{2}+\left(y_{1}-y_{2}\right)^{2}}
$$

Pengalokasian kembali data kedalam masingmasing kelompok pada metode $K$-means didasarkan pada perbandingan jarak antara data dengan centroid setiap kelompok yang ada. Data dialokasikan kembali ke kelompok yang mempunyai centroid dengan jarak terdekat dari data tersebut. Alokasi data ini ditentukan melalui persamaan berikut :

$$
a_{i 1}=\left\{\begin{array}{rr}
1, & d=\min \left\{D\left(X_{i}, C_{i}\right)\right\} \\
0, & \text { lainnya }
\end{array}\right.
$$


Dimana $a_{i 1}$ merupakan nilai keanggotaan titik $x_{1}$ ke pusat kelompok $C_{i}$, d adalah jarak terpendek dari data $x_{1}$ ke K kelompok setelah dibandingkan, dan $C_{i}$ adalah centroid ke-1. Fungsi objektif yang digunakan untuk metode K-means ditentukan berdasarkan jarak dan nilai keanggotaan data dalam kelompok. Persamaan fungsi objektif sebagai berikut :

$$
J=\sum_{i=0}^{n} \sum_{i=1}^{k} a_{i c} D\left(x_{i}, c_{i}\right)^{2}
$$

Dimana $\mathrm{n}$ adalah jumlah data, $\mathrm{k}$ adalah jumlah kelompok, $a_{i c}$ adalah nilai keanggotaan titik data $x_{i}$ ke kelompok $c_{i}$ yang diikuti, $a_{i c}$ mempunyai nilai 1 jika data adalah anggota kelompok dan 0 jika data bukan anggota.

\section{Analisis Cluster $\mathbf{K}$-Means Jarak Manhattan}

Analisis klaster pada data longitudinal berbeda dengan analisis klaster pada data cross section, dalam klasterisasi ini algoritma yang digunakan harus dapat mendukung struktur data panel. Metode $K$-Means dapat digunakan dalam pengelompokan data panel dengan memodifikasi ukuran jarak yang disesuaikan dengan struktur data panel. Namun, ada beberapa pendekatan yang dapat digunakan untuk klastering data panel. Jarak Manhattan memiliki kinerja yang paling optimum dibanding jarak Maximum, Frechet, Eucledean, dan Dynamic Time Wrapping. Jarak Manhattan didefinisikan pada persamaan berikut dengan $\mathrm{p}=1$ :

$$
\operatorname{Dist}\left(y_{1 . .}, y_{2 . .}\right)=\sum_{j=1}^{T} \sum_{X}^{M}\left[y_{1 j X}-y_{2 j X}\right]
$$

Jarak maksimum diperoleh dengan limit $\mathrm{p} \rightarrow+$ $\infty$, dengan persaman sebagai berikut :

$$
\begin{aligned}
\operatorname{Dist}\left(y_{1 . .}, y_{2 . .}\right) & =\left\{\sum _ { j = 1 } ^ { T } \sum _ { X } ^ { M } \left[y_{1 j X}\right.\right. \\
& \left.\left.-y_{2 j X}\right]^{p}\right\}^{\frac{1}{p}}, p \rightarrow \infty
\end{aligned}
$$

Pada penelitian ini jumlah klaster tidak ditentukan. Untuk melihat jumlah klaster yang optimal digunakan kriteria nilai Calinski dan
Harabasz. Kriteria Calinski dan Harabasz diberikan pada persamaan berikut[9] :

$$
C(k)=\frac{\operatorname{Trace}(B)}{\operatorname{Trace}(W)} \frac{n-k}{k-1}
$$

\section{METODE}

Data yang digunakan adalah data sekunder yang didapatkan dari website BPS dengan objek pengamatan 24 kabupaten/kota di Sulawesi Selatan pada periode tahun 2010-2020. Adapun variabel-variabel yang diperhatikan adalah IPM Perempuan $\left(X_{1}\right)$, IPG $\left(X_{2}\right)$, dan IDG $\left(X_{3}\right)$.

\section{ProsedurPenelitian}

Prosedur penelitian ini dijelaskan sebagai berikut:

1. Menginputkan data dalam bentuk matriks.

2. Proses analisis Cluster Longitudinal menggunakan metode $K$-Means.

3. Menentukan jumlah cluster optimum menggunakan kriteria nilai Calinski dan Harabasz.

4. Menentukan kemiripan objek menggunakan jarak Manhattan.

5. Melakukan interpretasi dengan melihat nilai centroid untuk menentukan kategori masing - masing cluster.

6. Mengklasifikasikan kelompok-kelompok yang terbentuk berdasarkan kategori dengan metode distribusi frekuensi numerik yang disusun berdasarkan interval.

\section{PEMBAHASAN}

\section{Profil Data}

Terdapat 24 kabupaten/kota di Sulawesi Selatan sebagai objek pengamatan pada periode waktu 2010-2020, yang akan diklasterkan dengan analisis cluster longitudinal.

\section{Cluster Optimum}

Jumlah kelompok tidak ditentukan, sehingga untuk menentukan jumlah kelompok optimum digunakan nilai kriteria Calinski dan Harabasz. Pada Tabel 4.1 terlihat nilai optimum terbentuk pada cluster 6 dengan nilai 18,675. 
Tabel 4.1 Calinski \& Harabsz Criterion

\begin{tabular}{cc}
\hline Jumlah Cluster $(k)$ & Nilai CH \\
\hline 2 & 17,924 \\
3 & 15,058 \\
4 & 17,210 \\
5 & 16,925 \\
6 & 18,675 \\
7 & 17,238 \\
8 & 15,761 \\
9 & 15,568 \\
10 & 15,152 \\
\hline
\end{tabular}

Hasil dari clustering membentuk 6 kelompok dengan karakteristik yang homogen antaranggota dan heterogen antarkelompok. Rincian anggota dan jumlah kelompok yang terbentuk dapat dilihat pada Tabel 4.2 yang menunjukkan Cluster A yang memiliki anggota terbanyak dengan 7 anggota dan Cluster $\mathrm{F}$ yang hanya memiliki 1 anggota.

\section{Tabel 4.2 Hasil Analisis Cluster}

\begin{tabular}{clc}
\hline Cluster & \multicolumn{1}{c}{ Kabupaten/Kota } & $\begin{array}{c}\text { Jumlah } \\
\text { Anggota }\end{array}$ \\
\hline A & $\begin{array}{l}\text { Kepulauan Selayar, } \\
\text { Jeneponto, Maros, } \\
\text { Pangkep, Bone, Wajo, }\end{array}$ & 7 \\
& $\begin{array}{l}\text { Luwu } \\
\text { Bulukumba, Sinjai, } \\
\text { Barru, Sopeng, Pinrang, } \\
\text { Enrekang } \\
\text { Takalar, Gowa, Tana } \\
\text { Toraja, Toraja Utara } \\
\text { Sidenreng Rappang, }\end{array}$ \\
D & 6 \\
Luwu Utara, Luwu \\
Timur \\
Makassar, Parepare, \\
Palopo \\
Bantaeng
\end{tabular}

\section{Klasifikasi Cluster}

Clustering kabupaten/kota di Sulawesi Selatan pada periode waktu 2010-2020 yang menghasilkan 6 cluster dengan mean masingmasing cluster seperti pada Tabel 4.3 yang selanjutnya akan diklasifikasikan menggunakan tabel distribusi.

Tabel 4.3 Mean hasil Clustering

\begin{tabular}{cccc}
\hline Mean & $X_{1}$ & $X_{2}$ & $X_{3}$ \\
\hline Cluster A & 62,55 & 90,06 & 61,86 \\
\hline
\end{tabular}

\begin{tabular}{llll}
\hline Cluster B & 66,20 & 96,29 & 63,43 \\
Cluster C & 60,24 & 85,82 & 66,71 \\
Cluster D & 65,17 & 89,47 & 46,68 \\
Cluster E & 75,62 & 95,60 & 68,47 \\
Cluster F & 63,86 & 96,00 & 77,55 \\
\hline
\end{tabular}

Setelah diperoleh mean dari masing-masing cluster, selanjutnya menentukan jumlah kelas, panjang kelas, dan rentang untuk menentukan batas-batas kategori pada tabel distribusi frekuensi numerik. Hasilnya dapat dilihat pada Tabel 4.4.

Tabel 4.4 Distribusi frekuensi numerik berdasarkan kategori

\begin{tabular}{llll}
\hline Kategori & \multicolumn{1}{c}{$X_{1}$} & \multicolumn{1}{c}{$X_{2}$} & \multicolumn{1}{c}{$X_{3}$} \\
\hline Rendah & $\mathrm{M}<64,37$ & $\mathrm{M}<88,31$ & $\mathrm{M}<55,97$ \\
Sedang & $64,37 \leq \mathrm{M}$ & $88,31 \leq \mathrm{M}$ & $55,97 \leq \mathrm{M}$ \\
& $\leq 69,49$ & $\leq 91,80$ & $\leq 66,26$ \\
Tinggi & $\mathrm{M}>69,49$ & $\mathrm{M}>91,80$ & $\mathrm{M}>66,26$ \\
\hline
\end{tabular}

Dari Tabel 4.4 setiap cluster dapat diklasifikasikan berdasarkan variabel $X_{1}, X_{2}$, dan $X_{3}$ dengan tiga kategori yaitu tinggi, rendah, dan sedang seperti yang ditunjukkan pada Tabel 4.5.

Tabel 4.5 Klasifikasi kategori setiap Cluster

\begin{tabular}{cccl}
\hline Kategori & \multicolumn{1}{c}{$X_{1}$} & \multicolumn{1}{c}{$X_{2}$} & \multicolumn{1}{c}{$X_{3}$} \\
\hline Cluster A & Rendah & Sedang & Sedang \\
Cluster B & Sedang & Tinggi & Sedang \\
Cluster C & Rendah & Rendah & Tinggi \\
Cluster D & Sedang & Sedang & Rendah \\
Cluster E & Tinggi & Tinggi & Tinggi \\
Cluster F & Rendah & Tinggi & Tinggi \\
\hline
\end{tabular}

Tabel 4.5 menyimpulkan bahwa cluster E merupakan cluster yang anggotanya berklasifikasi tinggi, dibuktikan dengan setiap variabelnya berkatori tinggi. Dapat diinterpretasikan bahwa cluster $\mathrm{E}$, pembangunan manusia yang berorientasi gender relatif tinggi. Berbeda dengan cluster $\mathrm{C}$ yang menunjukkan variabel $X_{1}$ dan $X_{2}$ berkategori rendah walaupun $X_{3}$ tinggi, yang menunjukkan bahwa pembangunan manusianya rendah dan ketimpangan gender tinggi. 


\section{KESIMPULAN}

Pembahasan hasil menunjukkan bahwa daerah perkotaan di Sulawesi Selatan relatif lebih sukses dalam pembangunan manusia berbasis gender, dapat dibuktikan dengan cluster E yang beranggotakan kota Makassar, Parepare, dan Palopo dengan kategori IPM perempuan, IPG, dan IDG yang relatif tinggi dibandingkan cluster lain. Sedangkan kabupaten pada cluster C, walaupun IDG-nya relatif tinggi namun capaian IPM perempuan dan IPG relatif rendah.

Pada kasus di cluster $\mathrm{F}$ yang beranggotakan kabupaten Bantaeng, capaian IPG relatif tinggi namun IPM-nya rendah, diharapkan pembangunan berbasis gender yang berkelanjutan dengan kategori sama-sama tinggi.

\section{DAFTAR PUSTAKA}

[1] Kementerian Perencanaan Pembangunan Nasional Republik Indonesia/Badan Perencanaan Pembangunan Nasional (Kementerian PPN/Bappenas), "Rencana Pembangunan Jangka Menengah Nasional 2020-2024", 2019.

[2] Badan Pusat Statistik (BPS), "Indeks Pembangunan Gender (IPG) 2020", 2021.

[3] Badan Pusat Statistik (BPS) Sulawesi Selatan, "Indeks Pembangunan Gender Provinsi Sulawesi Selatan 2019”, 2020.

[4] A.S. Awaluddin and I. Taufik, "Analisis Cluster Data Longitudinal pada pengelompokan daerah berdasarkan indikator IPM di Jawa Barat", Prosiding Seminar Nasional Metode Kuantitatif, 2017.

[5] A.S. Cahyani Sugiono, Indahwati, and I.M. Sumertajaya, "Comparison of multiple distances on panel data in nonhierarchical clustering method", International Journal of Scientific and Research Publication, vol 10:7, 2020.

[6] Kementerian Pemberdayaan Perempuan dan Perlindungan Anak Republik Indonesia, "Pembangunan Manusia Berbasis Gender", 2020.

[7] N.S. Wisnujati, "Penyusunan Indeks Pemberdayaan Gender dan Indeks
Pembangunan Kabupaten Bojonegoro", Jurnal Ilmu Ekonomi Universitas Wijaya Kusuma Surabaya, Vol. 20:2, 2020.

[8] I.M. Sumertajaya, "Analisis Gerombol Menggunakan Metode Two Steps Cluster", Forum Statistika dan Komputasi, Vol.12:1, 2007.

[9] C. Genolini, X. Alacoque, M. Sentenac, and C. Arnaud, "KML and KML3D:R Packages to Cluster Longitudinal Data", JSTATSOF, Vol.65:4, 2015. 